\title{
THE EFFECTS OF INFORMAL SALES MANAGEMENT CONTROLS ON THE LEARNING AND ENTREPRENEURIAL ORIENTATION WITHIN SALES
}

\author{
Susanne Spillecke, RWTH Aachen University, Germany \\ Malte Brettel, RWTH Aachen University, Germany
}

\begin{abstract}
Despite a large body of research on the importance of an organizational entrepreneurial orientation (EO) to firm performance (Rauch et al. 2009), little research has "open[ed] up the black box" of the organization (Monsen and Boss 2009, p. 71) and applied the concept of EO to specific functional units within a firm. This research gap is problematic because functional departments are like different "thought worlds" (Homburg and Jensen 2007) in regard to their orientations and competences. Furthermore, from a strategic management perspective the analysis of EO on the functional level is essential since, in order for entrepreneurship to be implemented as a "dominant logic", it must be "translated into the objectives, strategies, reward systems, control systems, planning approaches [and] structures" within the firm (Kuratko and Audretsch 2009, p. 5), all of which typically differ significantly from department to department.
\end{abstract}

This study adopts the concept of EO at the departmental level and investigates the sales department's entrepreneurial orientation (SEO) and learning orientation (SLO) and those orientations' impact on sales performance. Because of the importance of cultural and motivational factors for fostering learning and entrepreneurship, the authors propose informal controls as the levers that foster SEO and SLO. The sales department is selected as unit of analysis since it provides great opportunities for entrepreneurship and is a function in which entrepreneurship is critical (Morris et al. 1990). As the interface with the customer, salespeople have to cope with uncertainties and challenges from both inside and outside the organization. The challenges of the new selling environment also require companies take more of an entrepreneurial perspective than before (Ingram et al. 2005). SLO is investigated as a second strategic orientation since learning has shown to be an important source of competitive advantage. Beyond that, this study proposes SLO as driver of SEO since organizations or functional units can adapt and innovate only as fast as they are capable and willing to learn (Mavondo et al. 2005).

To examine the proposed effects of informal controls on SLO and SEO and their resulting effects on sales performance, this study used Structural Equation Modeling (SEM) based on survey data from 268 SMEs. The results of the study show that SEO and SLO are important levers with which to increase sales performance, and that informal controls are appropriate means for fostering SEO and SLO. Sales executives can promote learning and entrepreneurial behavior in their departments by encouraging collaboration and communication among salespeople and by creating an atmosphere in which salespeople can identify themselves with the company and its values.

This study complements existing EO research on the organizational level and underscores the importance of research on the more fine-grained effects of EO by calling for further studies on the antecedents and effects of EO in functional units.

References available upon request 